\title{
Roteiro dramático de Hélia Correia Reinvenção e originalidade
}

\author{
Sebastiana Fadda
}

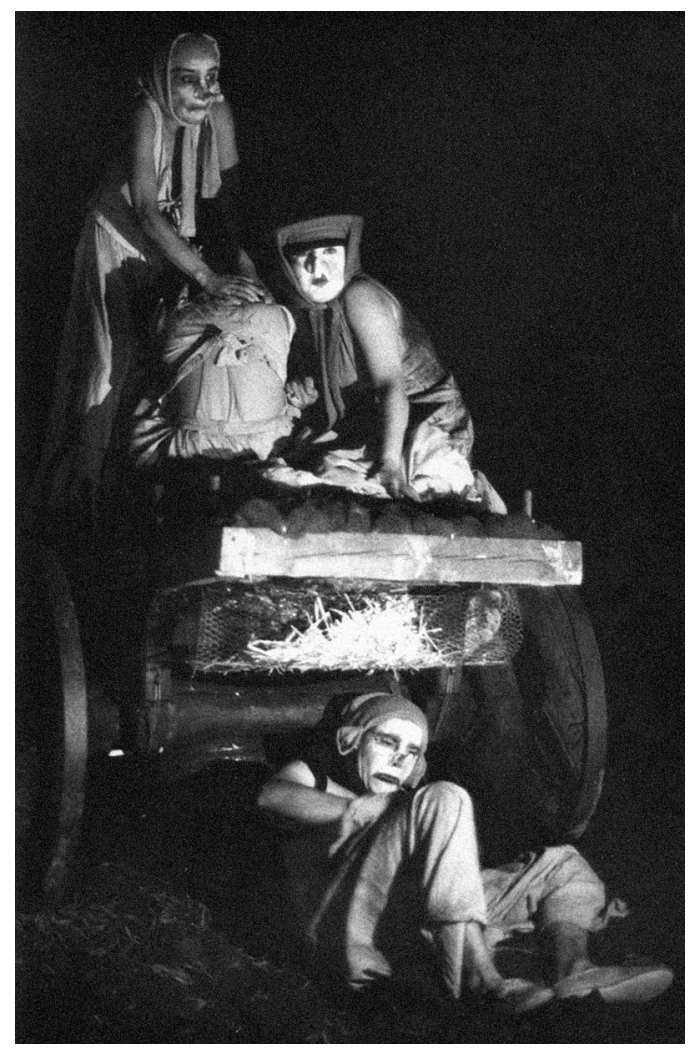

Escritora de reconhecido mérito, Hélia Correia afirmou-se no circuito literário português sobretudo como ficcionista. A critica mais insigne se, por um lado, aprecia a singular mistura de candura e malicia, a sábia dosagem entre imaginário fantástico e realismo potencial, por outro, detecta na sua obra a confluência da melhor tradição literária portuguesa (Camilo Castelo Branco, Augustina Bessa Luís, Maria Gabriela Llansol e José Saramago), de que seria porta-voz e continuadora. Franqueando-se da forte coerência temática inicial, que elegia os meios rurais como lugares privilegiados para fazer agir as suas personagens (desmistificando todavia as falsas imagens bucólicas projectadas pelos citadinos, inserindo as reivindicações da luta de classe), a autora ampliou progressivamente os limites postos nesses horizontes até admitir incursões históricas de amplo fôlego. 0 resultado é um percurso em ascensão, sólido e constante, que desde o já maduro 0 separar das águas (1981) atingiu o ápice com o encantamento efabulatório de Lillias Frazer (2002).

A produção de Hélia Correia, para além dos dois romances citados, inclui ainda as narrativas 0 número dos vivos (1982), A fenda erótica (1988, inicialmente publicada por episódios na imprensa periódica), A casa eterna (1991) e Insânia (1996); as novelas Montedemo (1983), Villa Celeste (1985) e Soma (1987); o conto Fascinação (2004); um livro de literatura para a infância, A luz de Newton (1988); dois livros de poesia, A pequena morte / Esse eterno canto (1986, díptico com Jaime Rocha) e Apodera-te de mim (2002).

Quanto ao teatro, regista-se uma adaptação ao palco da novela Montedemo (1987) por parte do encenador João Brites, para o grupo 0 bando. Recentes, assinadas pela autora e destinadas ao teatro para a infância e a juventude, as adaptações das peças shakespearianas Sonho de uma noite de verão (2003) e A ilha encantada (2005, editada em 2008, com base em A tempestade), levadas à cena pelo Teatro Nacional D. Maria II com encenação de João Ricardo. Uma notícia curiosa mas pertinente, tem ainda a ver com a participação de Hélia Correia como declamadora de textos em grego antigo no espectáculo Édipo Rei (1988), baseado numa tradução do original de Sófocles apresentado em Mérida (pela Comuna no anfiteatro romano, com encenação de João Mota) e depois trazida para Lisboa já no seu espaço da Praça de Espanha.

Os textos teatrais originais são poucos mas incisivos. Perdição: Exercicio sobre Antígona (1988), Florbela (1991), $O$ rancor: Exercício sobre Helena (2000) e Desmesura: Exercício com Medeia (2006) são dotados de uma forte carga trágica e literária, não apenas devido à linguagem e às temáticas, mas também pelo denso entrelaçar de referências eruditas (vindas da mitologia clássica, no caso dos três Exercícios) e historiográficas (baseadas na biobibliografia da poetisa Florbela Espanca, no caso de Florbela). Há ainda duas peças ligadas a dois projectos bem definidos. O segredo de Chantal (2006) resulta da iniciativa Panos: Palcos novos, palavras novas, promovida pela Culturgest, inspirada no projecto britânico Connections e destinada especialmente ao público escolar; nesta peça a autora imagina um futuro em que o livro, banido do quotidiano das pessoas, precisa de ser readmitido nas suas vidas. Por fim, Dicotomias (2008) é um monólogo hiperrealista levado à cena pelo Trigo Limpo - Teatro Acert e integrado no espectáculo Circonferências, de que fazia parte também um texto de Gonçalo M. Tavares, e por sua vez inscrito no projecto Interiores, pensado por aquela entidade de produção; seis escritores seriam convidados para redigirem textos originais para a criação de três espectáculos que, de alguma forma, cruzassem os textos, dois a dois. Sobre esta dramaturgia em geral, pode-se afirmar que se trata de um teatro cuja força impulsionadora está centrada na palavra - portanto no texto - e que põe
Montedemo, de Hélia Correia enc. João Brites, O bando, 1988 (Paula Só, Antónia Terrinha e Horácio Manuel), fot. Jorge Barros. 
Perdição: Exercicio sobre

Antigona

de Hélia Correia,

enc. João Mota, Comuna

- Teatro de Pesquisa, 1993

(Rita Salema

e Cármen Santos),

fot. Comuna / Jorge

Sequerra.

em causa tradições e lugares comuns de difícil erradicação, fornecendo novas chaves interpretativas dos mitos e das convenções.

Redigida em 1988, publicada em 1991 e levada à cena em 1993 pela Comuna - Teatro de Pesquisa com encenação de João Mota, Perdição: Exercício sobre Antígona é uma peça que reflecte sobre a ocultada força feminina.

A transgressão e a vitória sobre a tradição patriarcal - que faz da mulher um apêndice submetido ao poder masculino - estão explicitadas pelos rituais das bacantes. Em consonância com o modelo da tragédia clássica, a narração evidencia o sentido de desagregação que mina não apenas o microcosmo familiar, mas toda a estrutura social. Daí resulta uma Antígona iluminada sobretudo no seu aspecto frágil e humano, mais do que na sua dimensão enérgica e heróica. Essas peculiaridades estão ligadas à afirmação do poder feminino e à subversão da ordem masculina, bem como ao eterno conflito entre instinto e razão.

Florbela é um diálogo para duas actrizes: uma irá encarnar a poetisa, a outra uma espécie de guia angélica que irá desmascarar as inquietações daquela alma complexa e as contradições da sua breve vida. Redigida em 1991 a convite de Natália Correia e finalizada para a realização dum espectáculo do grupo de teatro Maizum, a peça chegou ao palco em versão reduzida, integrada por textos e cartas de Florbela Espanca. Devido à imprevista impossibilidade de participação de uma segunda actriz, a natureza do diálogo de Hélia Correia ficou alterada e adaptada a um interlocutor masculino.

O rancor: Exercício sobre Helena dá continuidade ao olhar dedicado pela autora ao poliédrico universo das mulheres segundo os modelos transmitidos pelos mitos, praticando porém uma revisão baseada em perspectivas no feminino. 0 meio retratado, longe de devolver o requinte normalmente associado à cultura helénica, é bastante rude, tal como o é a linguagem utilizada pelas personagens, que agem obedecendo a imperativos ditados por paixões irrefreáveis. Não se refuta a visão que associa a guerra ao mundo dos homens e a paz ao das mulheres, mas o rancor chamado em causa já no título, é o sentimento dominante experimentado por todas as personagens convocadas em cena por Hélia Correia, sejam elas homens ou mulheres. A protagonista, a quem está confiada a tarefa de desmentir lugares comuns, é a bela Helena, presumida responsável pela guerra de Tróia, aqui diminuída na sua divindade e exaltada na sua humanidade. Maltratada pela mitologia clássica, a sua figura encontra-se aqui reabilitada, de modo que a fuga com Páris é considerada mero pretexto para justificar uma guerra, motivada não pela defesa da honra de Menelau, mas antes pela agressividade e instinto guerreiro dos homens, que cedem à atracção pela luta e à medição animal das suas forças, para que se afirme (e consagre) a lei e o poder do mais forte. 0 sangue corre abundante, quer em público (entre estirpes antagonistas) quer no privado (no meio familiar), provocado por paixões excessivas e não mitigadas pela razão.

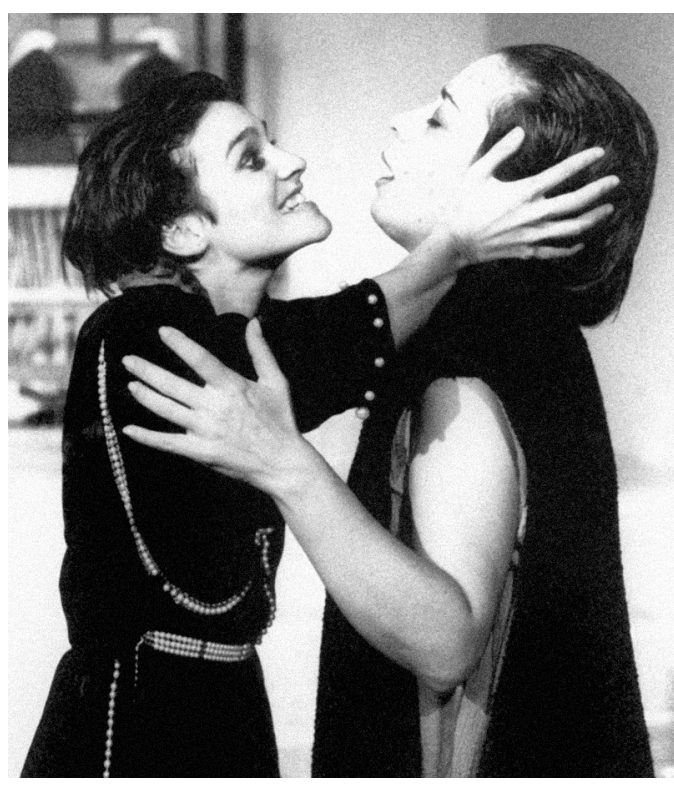

Desmesura: Exercício com Medeia revisita mais uma vez o universo mítico grego ampliando a sua amostra de mulheres singulares, marcadas por destinos trágicos e portadoras de energias telúricas poderosas. Filhas de deuses ou escravas, estas mulheres têm como sina a solidão, acabando humilhadas e ofendidas por homens que desprezam a sua entrega, e que mais cedo ou mais tarde Ihes mostram que o abandono é a outra face do desejo, e que a este se segue aquele. Mas nem todas se resignam e baixam a cabeça, havendo algumas que, tendo perdido tudo, sabem que já nada têm a perder, e tendo já sido derrotadas, podem suportar uma derrota definitiva. Medeia não castiga apenas o amado infiel: ao matar os filhos ela quer matar o amor que teve por Jasão, sendo esta ao mesmo tempo uma forma extrema de rejeitar quem a rejeita, castigando-se a si própria por o ter amado. Ela aceitara perder tudo o que tinha para o poder amar, e quando se vê obrigada a renunciar ao homem que ama, decide que a renúncia deve ser total. Ela, que é imortal, com a rejeição experimenta a morte dos mortais, e com a vingança condena-se a outro exílio sem retorno. Mas foi Eurípides quem alterou a tradição anterior a ele, segundo a qual eram os habitantes de Corinto que matavam os filhos da deusa como retaliação pelo assassínio da filha do seu rei. A Medeia "bárbara" - e castigada sobretudo pela sua diferença, pois nunca fora integrada como cidadã a todos os efeitos e com todos os direitos - torna-se assim a "estrangeira" que castiga e derrota quem sempre a quis expulsar.

$\mathrm{Na}$ atenta recensão a esta peça que Tatjana Manojlovic assinou para a Sinais de cena, fala-se em superioridade da protagonista, que "solta a sua raiva, desmesurada diante de um mundo de oportunistas e medíocres. Ao assassinar Abar e os filhos, Medeia destrói as suas únicas preciosidades - a lingua e o amor -, e aniquila a sua parte humana" (Manojlovic 2007: 107). É uma interpretação legítima e admissivel, certeira especialmente na sua conclusão, mas parece-me que a chave para a compreensão desta peça de Hélia Correia nos é dada pela própria dramaturga, no título escolhido: a desmesura é o traço distintivo da personalidade de Medeia e é nisso que ela é excepcional, não necessariamente superior, antes diferente. Toda a vida 


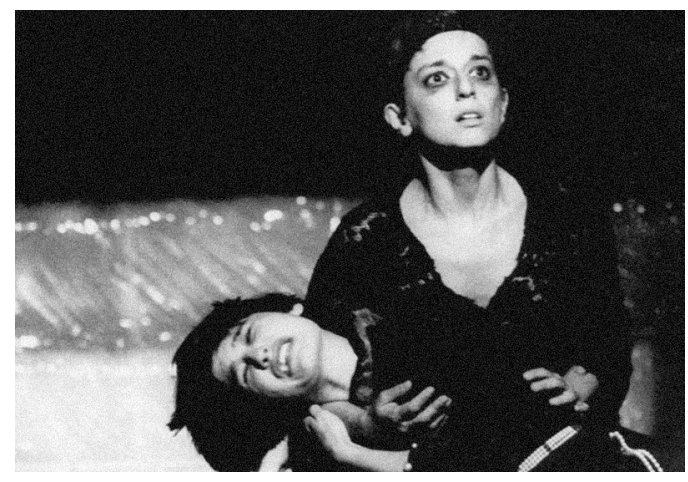

da feiticeira está aliás marcada pelo traço do excesso e pela adopção de decisões e comportamentos que não olham a meios para atingir os seus fins. Abar, a única ligação com as origens que permanecia na sua vida - pois a primeira lingua é um dos elementos identitários mais fortes e ao mesmo tempo é o meio de expressão da afectividade mais profunda - não passa de um obstáculo a ultrapassar para cumprir os seus desígnios finais. Implicitamente, portanto, Medeia renuncia quer à identidade adquirida quer, mais uma vez, à sua identidade mais íntima. Ao matar, mata o amor, inclusive por si própria, para que Jasão experimente a dor desmedida que ela também sente. E no apelo final, dirigido aos cidadãos gregos, para que contem a sua história até que alguém a compreenda, ciente do horror que as suas acções suscitam nos espectadores, ela está talvez a pedir alguma compaixão, porque o seu destino foi moldado por uma natureza incontrolável, que a levou a magoar e perder todos aqueles que amava, bem como a magoar-se e a perder-se. Porque não é impunemente que se sente em excesso.

0 que é certo é que Hélia Correia, na releitura pessoal que faz dos mitos, insere uma compreensão sensivel do universo das suas heroínas, da qual surge também uma certa solidariedade com elas, subvertendo as expectativas clássicas: Antígona, Helena e Medeia mereceriam admiração, consolação ou perdão pelos seus destinos marcados, afinal, pela força do dever, do afecto, dos deveres implícitos na (ou para a) concretização dos afectos, ou, no caso da deusa, por uma natureza destruidora que a leva em direç̧ão do abismo. Mas esta obra - ou antes este tríptico - já estimulou reflexões originais e de grande interesse, que foram reunidas no livro Furor: Ensaios sobre a obra dramática de Hélia Correia (2006), coordenado por Maria de Fátima Sousa e Silva, amostra significativa das múltiplas hipóteses de leitura destas peças singulares, observadas sob perspectivas diversificadas e por olhares sabedores, que cruzam o classicismo do tema com a modernidade e peculiaridade da sua reinterpretação.

Outra parte relevante, e mais heterogénea, da produção dramática de Hélia Correia é o teatro para a infância e a juventude, que inclui as duas adaptações shakespearianas e o original já referidos: Sonho de uma noite de verão, $A$ ilha encantada e 0 segredo de Chantal. Nestas peças, a dramaturga procede ao tratamento do género tão específico e delicado em que se inscrevem, pondo-o num plano de horizontalidade com o teatro destinado a outras idades, deixando entender que o considera como tendo direito a um igual reconhecimento da sua dignidade artística. Os destinatários, pois, não são vistos apenas como pequenos adultos em potência a quem ainda faltam demasiados

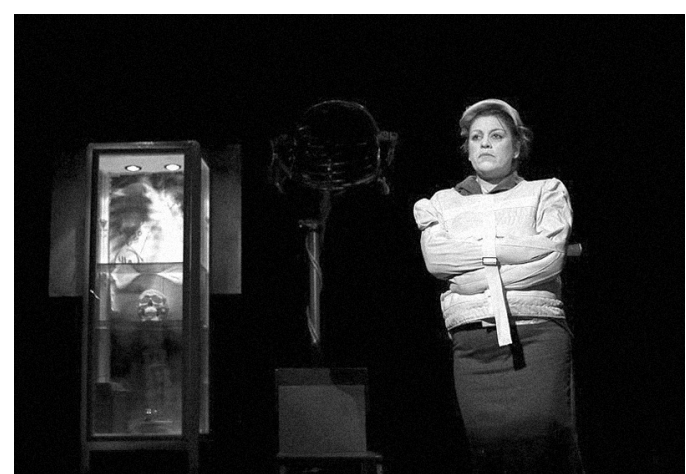

Perdição. Exercicio sobre Antigona, de Hélia Correia, enc. João Mota, Comuna - Teatro de Pesquisa, 1993 (Rita Salema e Manuela Couto), fot. Comuna / Jorge Sequerra.

atributos para serem completos. Hélia Correia não faz concessões facilitistas ou minorativas da inteligência já inteira do jovem público. E esta atitude é visivel nas duas adaptações de Shakespeare, podendo-se também inferir pelo esclarecimento acerca da estratégia tradutória adoptada, tal como explicitado na nota prefacial que tem o título expressivo de "No mistério de um texto", que antecede a mais recente tradução editada por Hélia Correia, A ilha encantada: "Segui o texto o mais de perto que consegui, em forma e em conteúdo. Não tive a intenção do o simplificar, a não ser em certos pormenores de estrutura ou de alongamento muito secundário" (p. 10). Essa recusa de simplificar, que afinal encerra a recusa da dramaturga e tradutora em infantilizar o texto, diminuindo num só gesto o autor e os destinatários, foi uma decisão com final feliz, porque do mistério do original surgiu o encanto da versão portuguesa e a preservação de um teatro imaginativo e poético. E a concessão feita à liberdade da adaptação, aceitando-se a adopção de uma nova designação para a peça - devendo-se porém a definição do lugar onde se desenrola a acção ao próprio Shakespeare -, pode ir mais longe, condensando numa extrema sintese a alusão, talvez, aos mistérios maiores do palco, da vida, e do palco da vida, onde todos vamos desempenhando ao mesmo tempo o papel de actores e espectadores do mesmo sonho, oscilando entre Ariel e Caliban.

\section{Referências bibliográficas}

CORREIA, Hélia (1991), Perdição: Exercicio sobre Antigona, seguido de

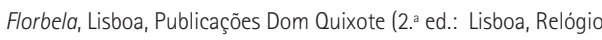
d'Água, 2006).

-- (2000), O rancor: Exercício sobre Helena, Lisboa, Relógio d'Água.

-- (2003), Sonho de uma noite de verão (versão para a infância a partir do original de William Shakespeare), Lisboa, Relógio d'Água.

-- (2006), Desmesura: Exercicio com Medeia, Lisboa, Relógio d'Água.

-- (2006), "O segredo de Chantal", in AA.W., Panos: Palcos novos, palavras novas, Lisboa, Livros Cotovia / Culturgest.

-- (2008), A ilha encantada (versão para a infância a partir do original A tempestade de William Shakespeare), Lisboa, Relógio d'Água.

-- (2008), Dicotomias, peça inédita, gentilmente facultada pela autora.

MANOJLOVIC, Tatjana (2007), "A peça bilingue de Hélia Correia", Sinais de cena, n. 7, Junho, pp. 106-107.

SILVA, Maria de Fátima Sousa e (coord.) (2006), Furor: Ensaios sobre a obra dramática de Hélia Correia, Coimbra, Imprensa da Universidade de Coimbra - Coimbra University Press.
Dicotomias,

texto de Hélia Correia integrado no espectáculo Circonferências, enc. Pompeu José, Trigo Limpo - Teatro ACERT, 2008 (Ilda Teixeira), fot. Carlos Teles. 